OPEN ACCESS

Edited by:

Mario Pena,

National University of Distance Education (UNED), Spain

Reviewed by:

Shen Liu,

University of Science and

Technology of China, China

Lin Zhang,

Ningbo University, China

*Correspondence:

Lumei Tian

tianlumei@sina.com

Specialty section:

This article was submitted to Educational Psychology, a section of the journal

Frontiers in Psychology

Received: 07 January 2019 Accepted: 25 February 2019

Published: 20 March 2019

Citation:

Liu L, Wang N and Tian L (2019) The Parent-Adolescent Relationship and Risk-Taking Behaviors Among Chinese Adolescents: The Moderating Role of Self-Control. Front. Psychol. 10:542. doi: 10.3389/fpsyg.2019.00542

\section{The Parent-Adolescent Relationship and Risk-Taking Behaviors Among Chinese Adolescents: The Moderating Role of Self-Control}

\author{
Lu Liu, Na Wang and Lumei Tian* \\ School of Psychology, Shandong Normal University, Jinan, China
}

The present study primarily aimed to examine whether self-control serves as a moderator in the associations between parent-adolescent relationships, including parental support and parent-adolescent conflict, and risk-taking behaviors among adolescents. The 917 Chinese adolescents whose mean age was 14.38 years $(S D=1.69)$ completed questionnaires effectively. The results indicated that the relationships between either parental support or parent-adolescent conflict and adolescent risk-taking behavior were moderated by self-control. Among those adolescents with lower levels of self-control, both higher levels of parent-adolescent conflict and lower levels of perceived parental support predicted more risk-taking behaviors, but their predicting roles got weakened with the increase of the level of self-control. Accordingly, good parent-adolescent relationship, particularly less parent-adolescent conflict, is critical for decreasing adolescent risk-taking. Otherwise, improving self-control is particularly helpful to those adolescents having more conflict with their parents or less parental support to decrease their risk-taking.

Keywords: Chinese adolescents, parent-adolescent conflict, perceived parental support, risk-taking behaviors, self-control

\section{INTRODUCTION}

Risk-taking behaviors refers to participating in behaviors which probably lead to some aversive consequences (Boyer, 2006). In general, it includes negative risk-taking behaviors, sometimes called problem behaviors, and positive risk-taking behaviors that is challenging but relatively socially acceptable (Özmen and Sümer, 2011). The former includes smoking, binge drinking, drug use and unsafe sexual behaviors, and so on, whereas the latter includes bungee jumping, skiing, and diving and other risky sports. During the last decade, scholars have paid much attention to negative risk-taking behaviors, such as alcohol use (O'Hara and Cooper, 2015; Passos et al., 2015), substance use (Jacobus et al., 2013; Wood et al., 2013), sexual risk taking (Downing and Bellis, 2009; O'Hara et al., 2012) and so on, because negative risk-taking behaviors not only do harm to adolescents' physical development but also have adverse impacts on their psychosocial adaptation. For comparison, the current study also put emphasis on negative risk-taking behaviors and tried to find out those risk factors or buffers for adolescent negative risk-taking behaviors. We did this job according to Problem-Behaviors Theory (PBT; Jessor, 1987), a psychosocial perspective focusing on the Personality System, the Environment System, and their interaction, 
which believes that individual behavioral performance needs to be studied from the perspective of development, as well as the interactions between the three systems.

Self-control is an important factor in the Personality System, which is defined as the ability of human beings to suppress automatic, habitual or innate behaviors, impulsiveness, emotion, or desire, otherwise these behaviors will interfere with target oriented behaviors (Muraven et al., 2006), which glasses a struggle between urges, desires, and inhibitory forces (Hofmann and Van Dillen, 2012). That is to say, individuals with high self-control are theorized to have abilities to inhibit impulses and resist immediate pleasures (Hay and Forrest, 2008), while individuals with low self-control including traits like urges and feeling seeking (Doran et al., 2011) are thought to be the opposite. Meanwhile, the role of self-control in adolescent adjustments has obtained much attention empirically. For example, higher level of self-control is correlated with better physical and mental health (Tu and Yang, 2016); increased self-control is linked to decreased aggression (Keatley et al., 2017) and reduced involvement in gambling behaviors among adolescents (Belle and Tammie, 2015); there are significant negative correlations between self-control and school violence (Agbaria and Daher, 2015; Zimmerman et al., 2015); those adolescents whose impulse control deteriorated during secondary school also had a higher risk of using substances during high school (James et al., 2016). Accordingly, the current study also took self-control into great account linked with adolescent risk-taking behaviors.

One of contextual factors that may have great influences on adolescents is family. Of particularly important is parentadolescent relationship. As a positive feature, parental support for basic psychological needs has a positive relationship with the Psychosocial adaptation of children and adolescents ( $\mathrm{Tu}$ et al., 2016). Parents mostly provide emotional and instrumental support for adolescents and build psychological connections with them (Shakespeare-Finch and Obst, 2011), and emotional support is believed to promote children's internalization of social values and criterions (Patterson et al., 1989), making children more sensitive to social hints before action. Instrumental support is linked to practical assistance, playing a prominent role in offering advice and guidance to their children (Cheung and Sim, 2014). For example, Padilla-Walker et al. (2016) found that parental warmth was positively related to adolescents' pro-social behaviors; low instrumental support was associated with lower self-perception and higher level of depression (Wang et al., 2018), and there are negative associations between perceived parental support and behaviors problems (Yun et al., 2016), such as alcohol use (Maslowsky et al., 2016). Similarly, an inverse relationship has been found between perceived familial support and cigarette smoking (Hamid et al., 2015). However, the tendency of adolescents to think that parents are absolutely authoritative is declining (Fuligni and Eccles, 1993) and adolescents demand more autonomy (Laursen and Collins, 2004), leading to an increase in conflicts with parents (Steinberg and Morris, 2001). As Atkinson et al. (2005) put forward, when conflict took place during family discussions or communications, one's emotional circuits in the brain were stimulated at the same time and it became increasingly difficult for an individual to reset his or her mind. As a result, their attention to information of externalizing behaviors is not enough. Considerable research has revealed the relationship between conflict and negative consequences for adolescents. For example, it has been found that conflicts between parents and adolescents are related to antisocial behaviors (Sentse and Laird, 2010), alcohol use (Chaplin et al., 2012; Abar et al., 2014), etc. Note that positive features and negative features of relationships are independent, not opposite ends of a continuum (Laursen and Mooney, 2008), independently predict adolescent externalizing problems, internalizing problems, and academic achievement (Adams and Laursen, 2007). Thus, it is important to focus on the effects of the two aspects of parent-adolescent relationship, support, and conflict, simultaneously, on adolescent adjustments.

Based on PBT, when the proneness in the Personality System and the Environment System is taken together, the combination may generate psychosocial tendency to make the prediction and explanation of problem behaviors. For example, positive emotionality can act as a resilience effect of a connection between parent-child clash and material use of adolescents (Wills and Sandy, 2001). Also, the associations of perceived parental support with aggressive or delinquent behaviors tend to be negative for adolescents with high empathy but positive for those with low empathy (Van der Graaff et al., 2012). Among persons with good self-control, risk factors (such as negative life events) have a reduced impact on drug use (Wills et al., 2008). As an individual's self-control increases, they require less social support to achieve subjective well-being; however, those with lower levels of self-control experience the opposite (Zhang and Xing, 2007). It can be seen that selfcontrol can moderate the relationship between environmental factors and social adaptation. However, work examining whether adolescents varying in self-control are differentially influenced by parent-adolescent relationship, especially on adolescent risktaking behaviors, is really limited. To our knowledge, no studies have tested whether self-control moderates the association between parent-adolescent relationship and risk-taking behaviors among adolescents. Therefore, in consistent with research indicating that low studious control and conflict between parents and adolescents is a common risk factor for depression, as well as participating in antisocial behaviors in adolescents (Wang et al., 2013), parent-adolescent conflict and low level of self-control in the current study are also expected as risk factors for adolescent risk-taking behaviors. Also, according to the risk-enhancing model (Fergus and Zimmerman, 2005), low self-control, as a risky factor, increases risks of low level of parental support. Accordingly, we hypothesized that low level of perceived parental support and high level of parentadolescent conflict would increase adolescent risk-taking behaviors at low level of self-control while not at high level of self-control.

Lastly, note that adolescent risk-taking behaviors might predict parent-adolescent relationship as well. Transactional 
model provides theoretical support for this possibility, which holds that development is the result of a sustained and dynamic two-way interaction between individuals and their environmental experience (Sameroff and Mackenzie, 2003). A follow-up study on adolescents found that internalizing and externalizing problem behaviors in the pre-test significantly predicted parenting attitudes and behaviors in the post-test (Buist et al., 2004). A cross-lagged panel model also revealed a reciprocal association between mother-adolescent relationship quality and adolescent antisocial behaviors (Crocetti et al., 2016). Accordingly, we established a competitive model in which adolescent risk-taking behaviors were the predictor, while parent-adolescent relationship was the outcome and hypothesized that more risk-taking behaviors would lead to poorer parentadolescent relationship.

\section{MATERIALS AND METHODS}

\section{Participants}

The participants were recruited from a public secondary school and a public high school which were located in a county in Shandong Province in eastern China. They were all from rural areas. A total of 980 adolescents were invited as the initial sample. Among them, 917 adolescents completed the questionnaires, giving a response rate of $93.6 \%$. Therefore, the final sample consisted of 917 Chinese adolescent students from 11 to 19 years old (mean age $=14.38, S D=1.69 ; 493$ boys).

\section{Measures}

\section{Parent-Adolescent Relationship}

Perceived parental support or parent-adolescent conflict was measured using the Chinese shortened version (Tian et al., 2012) of the Network of Relationships Inventory (NRI; Furman and Buhrmester, 1985). It includes 15 items in both relationships with father and mother and is made up of five dimensions, including companionships (e.g., "How long are you with this person when you are free?"), instrumental help (e.g., "Does the person often give you help when in need?"), affection (e.g., "How much does the person like you?"), intimacy (e.g., "Do you share your secrets or feelings with the person?"), and conflict (e.g., "Is there much quarrel between your parent and you?"), each dimension consisting of three items. For each item, participants were asked to rate it on a 5-point Likert scale, ranging from 1 (little or none) to 5 (the most). Because the former four dimensions correlated highly with each other and correlations between the mother's and the father's scores were high as well $(0.46<r s<0.81, p<0.001)$ in the present study, scores of them were combined into a composite parental support score, according to the procedure of previous research (Furman et al., 2002; Rubin et al., 2004; Tian et al., 2012, 2014). With higher scores, the levels of parental support are higher, and its Cronbach's alpha coefficient was 0.94 . Similarly, we averaged the scores on mothers and fathers to compose one score for parent-adolescent conflict. The higher the score, the more serious the conflict between parents and adolescents, and its Cronbach's alpha coefficient was 0.90 . The Cronbach's alpha coefficient for the whole NRI was 0.91 in the present study. The fit indices from a confirmatory factor analysis were adequate, $\chi^{2} / \mathrm{df}=2.80, \mathrm{GFI}=0.97$, TLI $=0.98$, CFI $=0.98$, and RMSEA $=0.04$.

\section{Self-Control}

The Self-Control Scale for Chinese middle and high school students (SCS) was developed for assessing the ability of self-control of participants in learning, entertainment, and social life (Wang and Lu, 2004). It consists of 36 items (e.g., "I will shout and yell when I am happy" or "I am easily influenced by the outside"). For each statement, participants were asked to rate it on a 5-point Likert scale, ranging from 1 (completely disagree) to 5 (completely agree). With higher scores, the levels of self-control are higher. In the present study, the Cronbach's alpha coefficient of the SCS was 0.88 . The fit indices from a confirmatory factor analysis were adequate, $\chi^{2} / \mathrm{df}=2.80, \mathrm{GFI}=0.91$, TLI $=0.88, \mathrm{CFI}=0.90$, and RMSEA $=0.04$.

\section{Risk-Taking Behaviors}

The Chinese version (Zhang et al., 2011) of the Adolescent Risk-Taking Questionnaires (ARQ; Gullone et al., 2000) was used to measure the frequency of participation in each of some behaviors (on a 5-point Likert scale: $0=$ never done, $4=$ done very often). It consists of 17 items with a satisfactory reliability and validity that can be applied to the assessment of Chinese adolescent risk-taking behaviors (Zhang et al., 2011). It is comprised of four dimensions, including thrillseeking behaviors (five items, e.g., "going skating" or "going skiing"), reckless behaviors (two items, e.g., "drug abuse" or "unsafe sexy behaviors"), rebellious behaviors (six items, e.g., "smoking" or "alcohol use"), and antisocial behaviors (four items, e.g., "making fun of others" or "having cheated on school tests"). Thrill-seeking behaviors are regarded as positive or socially acceptable behaviors, while the last three dimensions are regarded as conveying negative risk-taking behaviors (Moore et al., 2004). Thus the last 3 dimensions were only investigated in the current study, and a risk-taking behaviors total score was calculated for each adolescent with a high score indicating more risk-taking behaviors. The Cronbach's alpha coefficient was 0.71 . The fit indices from a confirmatory factor analysis were adequate, $\chi^{2} / \mathrm{df}=3.22$, GFI $=0.96$, TLI $=0.94$, CFI $=0.95$, and RMSEA $=0.05$.

\section{Procedure}

In current research, data were collected by trained graduate students in participants' respective classrooms. Before survey, participants were informed that the study was anonymous and they could withdraw freely. The present study adopted a passive consent procedure recommended by Ellickson (1989), which requires students and their parents to return forms only when they do not want to participate in the study. Those who do not return the forms are assumed to agree to participate in 
the study. Then, all participants were given a series of selfreported questionnaires, and all measures were completed in approximately $20 \mathrm{~min}$. Ethics approval was obtained from the Research Ethics Boards at our university.

\section{Statistical Analysis}

After obtaining the descriptive statistics for the study variables and assessing the correlations among them, separate hierarchical linear regression analyses were conducted using SPSS Version 22 to examine the hypotheses. Gender was re-coded into dummy variables separately $(0=$ male, $1=$ female $)$. The scores on perceived parental support, parent-adolescent conflict, and self-control were all transformed into $\mathrm{Z}$ scores before creating the interaction items (Aiken and West, 1991). In the regression analysis, the predictors were entered in three hierarchical steps: (1) age and gender; (2) perceived parental support or parent-adolescent conflict and self-control; and (3) the two-way interaction item. Post-hoc probing of significant interactions was conducted using the simple slope analysis (Aiken and West, 1991) when the predictor criterion was examined at high (i.e., 1 standard deviation above the mean) and low (i.e., 1 standard deviation below the mean) levels of self-control.

\section{RESULTS}

\section{Common Method Biases}

The common-method bias might occur owing to all data in the present study deriving from adolescents' self-reports. Thus, when collecting the data, we made questionnaires anonymous and made some items reverse scoring. Prior to data analysis, Harman's one-factor test was conducted, in which 17 factors with one-above Eigen values were extracted; in addition, the first factor could explain $17.28 \%$ of the variance much lower than the critical value of $40 \%$. Therefore, there was no serious common-method bias in the current study.

\section{DESCRIPTIVE STATISTICS AND CORRELATION ANALYSIS}

Table 1 gives the means, standard deviations, and correlations of the study variables. Perceived parental support and selfcontrol were negatively associated with risk-taking behaviors

TABLE 1 | Descriptive statistics and correlations among study variables $(N=917)$.

\begin{tabular}{|c|c|c|c|c|c|}
\hline Variables & $M$ & $S D$ & 1 & 2 & 3 \\
\hline 1. Perceived parental support & 3.36 & 0.78 & 一 & & \\
\hline 2. Parent-adolescent conflict & 2.02 & 0.82 & $-0.16^{\star \star \star}$ & 一 & \\
\hline 3. Self-control & 3.30 & 0.48 & $0.26^{\star \star \star}$ & $-0.45^{\star \star \star}$ & 一 \\
\hline 4. Risk-taking behaviors & 0.35 & 0.39 & $-0.11^{\star \star}$ & $0.27^{\star \star \star}$ & $-0.40^{\star \star \star}$ \\
\hline
\end{tabular}

Note: ${ }^{* * *} p<0.001,{ }^{* *} p<0.01,{ }^{*} p<0.05$.
TABLE 2 | Hierarchical regression analysis for perceived parental support and self-control predicting risk-taking behaviors.

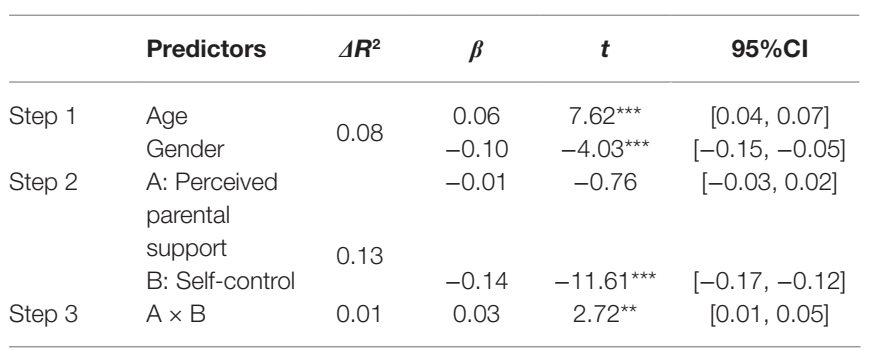

Note: ${ }^{* *} p<0.001,{ }^{* *} p<0.01,{ }^{*} p<0.05$.

$(r=-0.11, p<0.001 ; r=-0.40, p<0.001)$, whereas parentadolescent conflict was positively correlated with risk-taking behaviors $(r=-0.16, p<0.001)$. The effects of gender $(t$ $(915)=4.00, p<0.001)$ and age $(r=0.25, p<0.001)$ on risk-taking behaviors were both significant and thus were controlled statistically in the next analyses.

\section{TESTING THE MODERATION MODELS}

As shown as in Table 2, there was a negative main effect of self-control and a significant interaction between perceived parental support and self-control on adolescent risk-taking behaviors. Simple slope analyses (See Figure 1) indicated that perceived parent support was associated with risk-taking behaviors marginally significant at low levels of self-control $\left(b_{\text {simpleslope }}=-0.04, t=-1.68, p=0.09\right)$, but the association was not significant statistically at high levels of self-control $\left(b_{\text {simpleslope }}=0.03, t=1.29, p=0.20\right)$.

As shown as in Table 3, however, there were a positive main effect of parent-adolescent conflict on risk-taking behaviors and a negative main effect of self-control on risk-taking behaviors, as well as the significant interaction between them. Simple slope analyses (See Figure 2) indicated that among those adolescents with low levels of self-control, greater levels of parent-adolescent conflict predicted more risk-taking behaviors $\left(b_{\text {simple slope }}=0.07, t=3.63, p<0.001\right)$, but the association was not significant statistically among those with high levels of self-control $\left(b_{\text {simple slope }}=0.03\right.$, $t=1.39, p=0.16$ ).

To test the competitive model, we also used regression analysis, in which risk-taking behaviors was the independent variable and parent-adolescent relationship was the outcome variable. The analyses indicated that there was a negative main effect of risk-taking behaviors on perceived parental support and a positive main effect on parent-adolescent conflict $\left(\beta=-0.10, p<0.001, R^{2}=0.02 ; \beta=0.23, p<0.001\right.$, $R^{2}=0.09$, respectively), but their effect sizes $\left(R^{2}\right)$ were much smaller than those in the hypothesized model $\left(R^{2}=0.09\right.$, $\left.R^{2}=0.15\right)$. The interaction between risk-taking behaviors and self-control was not obvious $(p=0.65 ; p=0.12)$, which indicated that the competitive moderation model was not well established. 


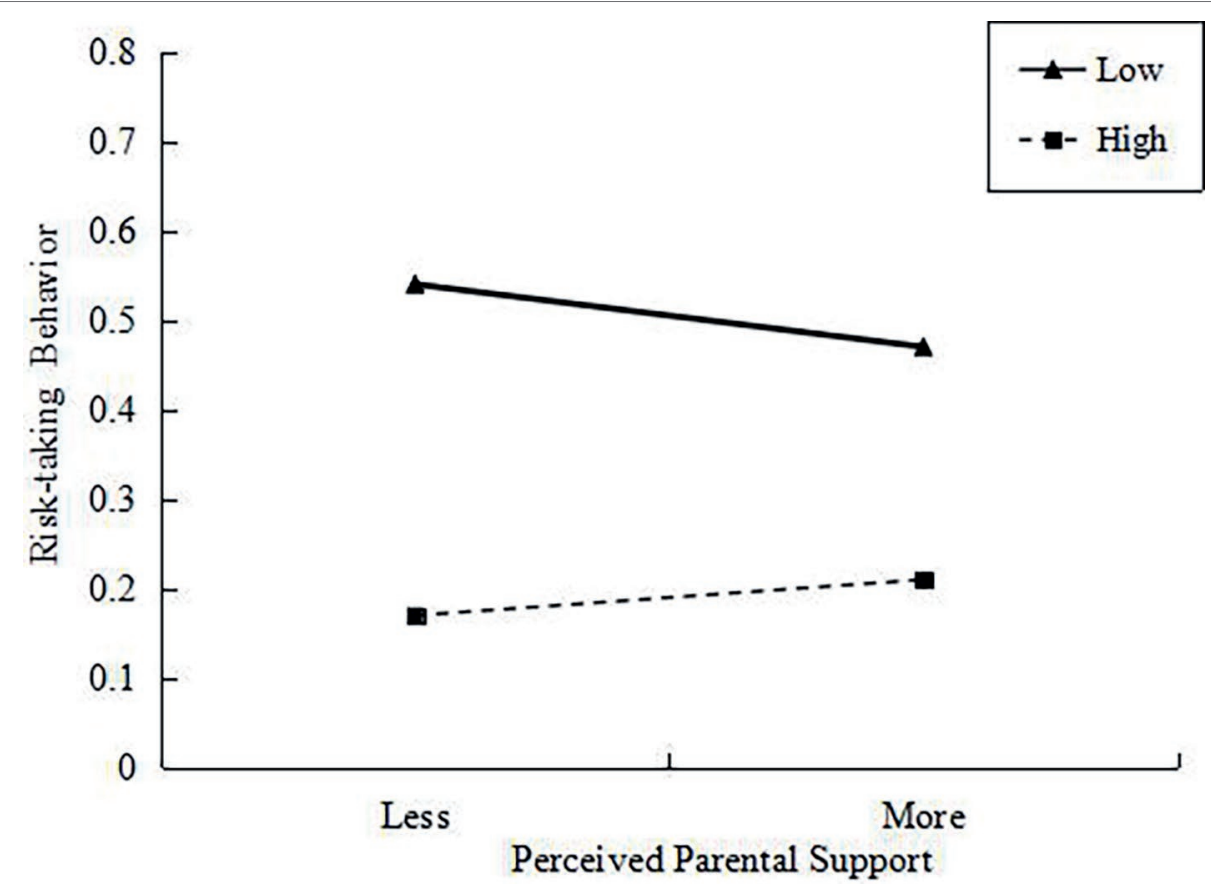

FIGURE 1 | Interaction between perceived parental support and self-control on adolescent risk-taking behaviors.

TABLE 3 | Hierarchical regression analysis for parent-adolescent conflict and self-control predicting risk-taking behaviors.

\begin{tabular}{|c|c|c|c|c|c|}
\hline & Predictors & $\Delta R^{2}$ & $\beta$ & $t$ & $95 \% \mathrm{Cl}$ \\
\hline Step 1 & $\begin{array}{l}\text { Age } \\
\text { Gender }\end{array}$ & 0.08 & $\begin{array}{c}0.06 \\
-0.10\end{array}$ & $\begin{array}{c}7.61^{\star \star \star} \\
-4.03^{\star \star \star}\end{array}$ & $\begin{array}{c}{[0.04,0.07]} \\
{[-0.15,-0.05]}\end{array}$ \\
\hline Step 2 & $\begin{array}{l}\text { A: Parent- } \\
\text { adolescent } \\
\text { conflict } \\
\text { B: Self- } \\
\text { control }\end{array}$ & 0.15 & -0.12 & $-9.39^{\star \star \star}$ & {$[-0.15,-0.10]$} \\
\hline Step 3 & $A \times B$ & 0.01 & -0.02 & $-2.31^{*}$ & {$[-0.05,-0.004]$} \\
\hline
\end{tabular}

Note: ${ }^{* * *} p<0.001,{ }^{* *} p<0.01,{ }^{*} p<0.05$.

\section{DISCUSSION}

The main goal of the present study was to examine the associations of parent-adolescent relationships, including parental support and parent-adolescent conflict, with adolescents risktaking behaviors and the moderating role of self-control. Overall, the results indicated that for those adolescents with lower levels of self-control, both higher levels of parent-adolescent conflict and lower levels of perceived parental support predicted more risk-taking behaviors, but their predicting roles got weakened with the increase of the level of self-control. Additionally, parent-adolescent conflict was significantly related to adolescents risk-taking behaviors, whereas the relationship between parental support and risk-taking behaviors was not obvious.

First, in agreement with previous research reporting that increased self-control is linked to decreased aggression (Keatley et al., 2017), self-control was also negatively correlated with adolescent risktaking behaviors in the present study. This is possibly because adolescents lower in self-control have more traits like impulses and feeling seeking (Doran et al., 2011), which in turn making them more likely to ignore potential passive consequences of their behaviors (Watson and Clark, 1993).

Second, in accordance with research regarding parentadolescent relationship as important in moulding adolescent mental functioning (Lam et al., 2012; Skinner and Mchale, 2016), high levels of parent-adolescent conflict were associated with more risk-taking behaviors in the present study. When adolescents have more disagreements or conflicts with their parents, emotional circuits in the brain are stimulated (Atkinson et al., 2005), such as causing anger (Chaplin et al., 2012), then easily resulting in heightened risk taking. Chein et al. (2011) have also found that negative environmental factors (e.g., the existence of peers) enlarge adolescents' ventral striatum activation, resulting in much risk-taking behaviors. Another possible explanation is that high level of parent-child conflict will bring children a negative worldview, which easily causes some externalizing problem behaviors (Vanassche et al., 2014).

Third and importantly, as expected by PBT, the impact of parent-adolescent conflict was qualified by adolescent self-control. Specifically, high levels of parent-adolescent conflict predicted increases in adolescent risk-taking behaviors at low levels of self-control, but this predicting role got weakened at high levels of self-control. This result is in line with previous studies finding that less control and parent-adolescent conflict indicate common risk factors for adolescent depression as well as engagement in misconduct (Wang et al., 2013). Furthermore, 


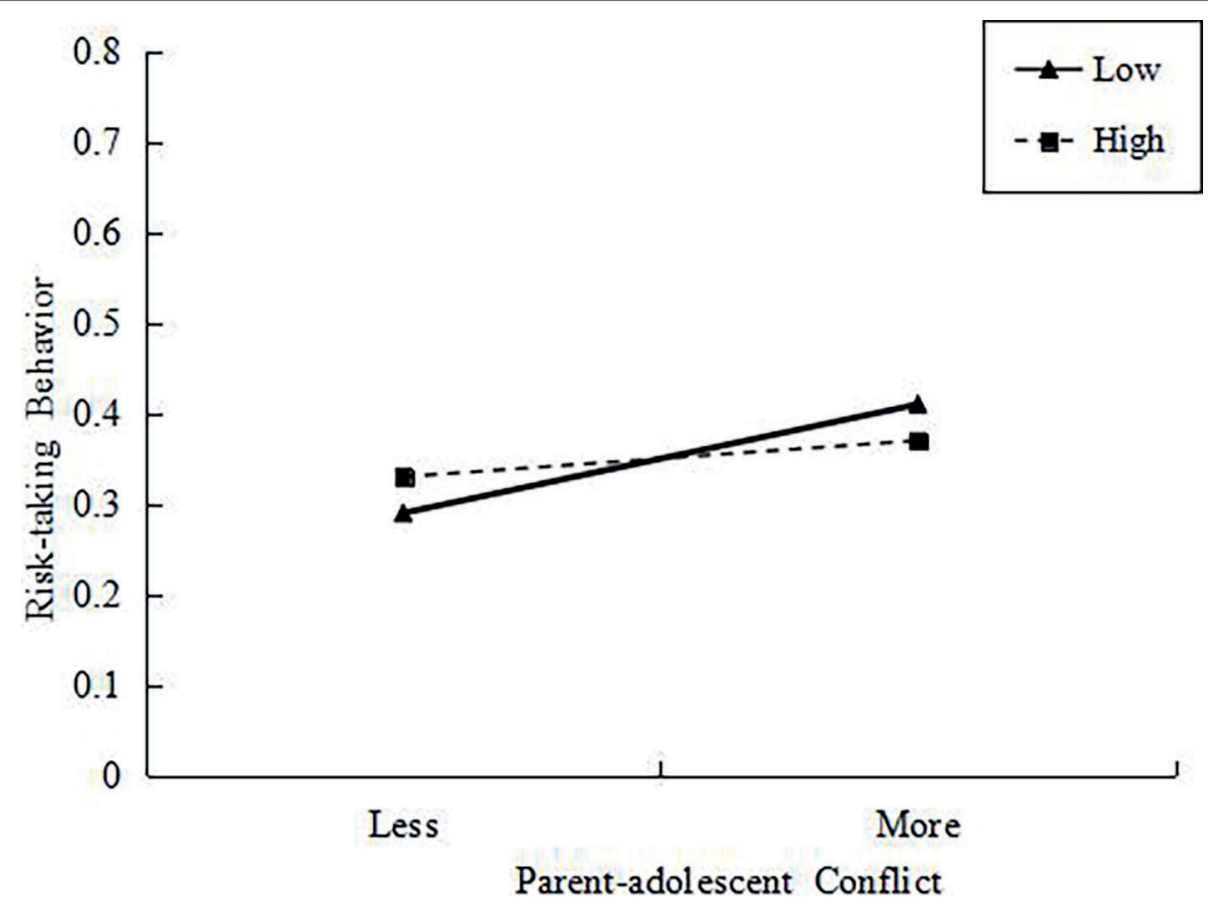

FIGURE 2 | Interaction between parent-adolescent conflict and self-control on adolescent risk-taking behaviors.

it also supports the risk-enhancing model (Fergus and Zimmerman, 2005), suggesting one risky factor will enhance the negative impact of another risky factor on adolescent development and adjustment. However, among those adolescents with high levels of self-control, self-control as a protective factor buffered the impact of parent-adolescent conflict on risk-taking behaviors.

Inconsistent with our expectation, increased perceived parental support was not linked to decreased risk-taking behaviors, even among those adolescents with high levels of self-control. A possible explanation is that low levels of perceived parental support of adolescents, particularly of Chinese adolescents who are usually only one child or have only one sibling in their family because of China's family planning policy, were not absolutely low ( $M=3.36 \pm 0.78$ in the current study) and thereby have no obvious difference in impacting adolescent risk-taking behaviors from those higher levels of perceived parental support. Also, it suggests that parental support is neither a protector nor a risky factor of adolescent risk taking because individuals during adolescence emphasize more on peer support rather than parental support (Macek and Jezek, 2007; Ju et al., 2011). The period of adolescence is in the transition period from school-age children to young adulthood. During this period, students have gradually transferred their main activities from family to social institutions such as schools, classrooms, and juvenile organizations. During this time, the closest relationship with the youth is the peer. At the low levels of self-control, however, lower perceived parent support was associated with more risk-taking behaviors marginally significantly, possibly because that both the factors may have synergistic effects and self-control is a stronger predictor of adolescent risk-taking behaviors than perceived parental support.
Therefore, it suggests that in adolescence, it is not enough to reduce risk-taking behaviors only relying on the environment, and that improving the internal personality power of individuals is a more fundamental way.

Finally, consistent with our hypothesis and prior studies (Buist et al., 2004; Crocetti et al., 2016), parent-adolescent relationship and risk-taking behaviors have a reciprocal relationship. However, the effect sizes $\left(R^{2}\right)$ in the hypothesized model were greater than those in the competitive model. Importantly, the competitive moderation model was not well-established. The result provided empirical evidence for the Problem-Behaviors Theory. Parentadolescent relationship as an important environmental factor has an important impact on adolescent risk-taking behaviors. The more conflict between parents and adolescents, the more risky-taking behaviors adolescents will be taken in their future life (Lam et al., 2012). This conclusion, however, should be accepted carefully before it is further examined, and more supportive evidence should be sought in future studies.

Lastly, there are some limitations to be noted in the present study. First, it was impossible to draw causal conclusions of the relationships between variables because of the cross-sectional design of the current study. Second, given that the particularity of Chinese context, it needs to be cautious to extend the present results to other cultural background. It would be of value to further examine the relationships in other countries or districts. Despite these limitations, the present study may offer a new sight into interaction between self-system and family system on adolescent development and adjustment, and these findings suggest that intervention and prevention measures devoted to decreasing adolescent risk-taking incorporate the interaction of family and personal characteristics. 
Despite these limitations, the findings of the current study provide valuable information. First, this study simultaneously examined the moderating roles of self-control in the relationships between both parental support and parent-adolescent conflict with adolescent risk-taking behaviors. The findings of the present study provide evidence for Problem-Behaviors Theory, extend our insight into the mechanisms underlying the associations among parent-adolescent relationships, self-control, and adolescent risk-taking behaviors, and supplement data for previous relevant studies. Second, the current study found that parent-adolescent relationship could predict adolescent risktaking behaviors and vice versa, which provides further support for transactional model. Finally, the findings may provide guidance for intervention and prevention of adolescent risktaking behaviors. The study suggests that to decrease adolescents' risk-taking behaviors we should focus on building good parentadolescent relationship and improving individual self-control, particularly the latter. It is important for adolescents to boost self-control training, cultivation, development, and promotion.

\section{REFERENCES}

Abar, C. C., Jackson, K. M., Colby, S. M., and Barnett, N. P. (2014). Parentchild discrepancies in reports of parental monitoring and their relationship to adolescent alcohol-related behaviors. J. Youth Adolesc. 44, 1688-1701. doi: 10.1007/s10964-014-0143-6

Adams, R. E., and Laursen, B. (2007). The correlates of conflict: disagreement is not necessarily detrimental. J. Fam. Psychol. 21, 445-458. doi: 10.1037/0893-3200.21.3.445

Agbaria, Q., and Daher, W. (2015). School violence among Arab adolescents in Israel and its relation to self-control skills and social support. Psychol. Rep. 117, 1-7. doi: 10.2466/16.21.PRO.117c12z2

Aiken, L. S., and West, S. G. (1991). Multiple regression: Testing and interpreting interactions. Thousand Oaks, CA: Sage.

Atkinson, B., Atkinson, L., Kutz, P., Lata, J., Lata, K. W., Szekely, J., et al. (2005). Rewiring neural states in couples' therapy: advances from affective neuroscience. J. Syst. Ther. 24, 3-16. doi: 10.1521/jsyt.2005.24.3.3

Belle, G. F., and Tammie, R. (2015). Contribution of positivity ratio and selfcontrol to reduced gambling severity among adolescents. Health Soc. Work 40, 209-216. doi: 10.1093/hsw/hlv042

Boyer, T. W. (2006). The development of risk-taking: a multi-perspective review. Dev. Rev. 26, 291-345. doi: 10.1016/j.dr.2006.05.002

Buist, K. L., Dekovic, M., Meeus, W., and Aken, M. A. G. V. (2004). The reciprocal relationship between early adolescent attachment and internalizing and externalizing problem behaviour. J. Adolesc. 27, 251-266. doi: 10.1016/j. adolescence.2003.11.012

Chaplin, T. M., Sinha, R., Simmons, J. S., Healy, S. M., Mayes, L. C., Hommer, R. E., et al. (2012). Parent-adolescent conflict interactions and adolescent alcohol use. Addict. Behav. 37, 605-612. doi: 10.1016/j.addbeh.2012.01.004

Chein, J., Albert, D., O'Brien, L., Uckert, K., and Steinberg, L. (2011). Peers increase adolescent risk taking by enhancing activity in the brain's reward circuitry. Dev. Sci. 14, 1-10. doi: 10.1111/j.1467-7687.2010.01035. x21499511

Cheung, H. S., and Sim, T. N. (2014). Social support from parents and friends for Chinese adolescents in Singapore. Youth Soc. 49, 548-564. doi: 10.1177/0044118X14559502

Crocetti, E., Moscatelli, S., Jolien, V. D. G., Keijsers, L., Van Lier, P., Koot, H. M., et al. (2016). The dynamic interplay among maternal empathy, quality of mother-adolescent relationship, and adolescent antisocial behaviors: new insights from a six-wave longitudinal multi-informant study. PLoS One 11:e0150009. doi: 10.6084/m9.figshare.3099829

Doran, N., Aldridge, A., Roesch, S., and Myers, M. (2011). Factor structure and invariance of the behaviorsal undercontrol questionnaire: testing for

\section{DATA AVAILABILITY}

All datasets generated for this study are included in the manuscript.

\section{AUTHOR CONTRIBUTIONS}

LL conducted measurements, data collection, data analysis, and completed the earlier draft of this manuscript. NW contributed to data analysis and revising the manuscript. LT provided a great amount of support and guidance in the research and revised the manuscript substantially.

\section{FUNDING}

This study was supported by National Social Science Foundation of China (Grant No. 16BSH103). differences across gender and ethnicity. Eur. J. Psychol. Assess. 27, 145-152. doi: 10.1027/1015-5759/a000060

Downing, J., and Bellis, M. A. (2009). Early pubertal onset and its relationship with sexual risk-taking, early pubertal onset and its relationship with sexual risk taking, substance use and anti-social behaviors: a preliminary crosssectional study. BMC Public Health 9:446. doi: 10.1186/1471-2458-9-446

Ellickson, P. L. (1989). Limiting nonresponse in longitudinal research: Three strategies for school-based studies (Rand Note N-2912-CHF). Santa Monica, CA: Rand Cooperation.

Fergus, S., and Zimmerman, M. A. (2005). Adolescent resilience: a framework for understanding healthy development in the face of risk. Annu. Rev. Public Health 26, 399-419. doi: 10.1146/annurev.publhealth.26.021304.144357

Fuligni, A. J., and Eccles, J. S. (1993). Perceived parent-child relationships and early adolescents' orientation towards peers. Dev. Psychol. 29, 622-632. doi: 10.1037/0012-1649.29.4.622

Furman, W., and Buhrmester, D. (1985). Children's perceptions of personal relationships in their social networks. Dev. Psychol. 21, 1016-1024. doi: 10.1037/0012-1649.21.6.1016

Furman, W., Simon, V. A., Shaffer, L., and Bouchey, H. A. (2002). Adolescents' working models and styles for relationships with parents, friends, and romantic partners. Child Dev. 73, 241-255. doi: 10.1111/1467-8624.00403

Gullone, E., Moore, S., Moss, S., and Boyd, C. (2000). The adolescent risktaking questionnaire: development and psychometric evaluation. J. Adolesc. Res. 15, 231-250. doi: 10.1177/0743558400152003

Hamid, A., Abbas, A. G., Asghar, M., and Pouran, N. (2015). Cigarette smoking and its relationship with perceived familial support and religiosity of university students in Tabriz. Iran. J. Psychiatry 10, 136-143. doi: 10.1002/ jez.1401060103

Hay, C., and Forrest, W. (2008). Self-control theory and the concept of opportunity: the case for a more systematic union. Criminology 46, 1039-1072. doi: 10.1111/j.1745-9125.2008.00135.x

Hofmann, W., and Van Dillen, L. (2012). Desire: the new hot spot in self-control research. Curr. Dir. Psychol. Sci. 21, 317-322. doi: 10.1177/0963721412453587

Jacobus, J., Thayer, R. E., Trim, R. S., Bava, S., Frank, L. R., and Tapert, S. F. (2013). White matter integrity, substance use, and risk taking in adolescence. Psychol. Addict. Behav. 27, 431-442. doi: 10.1037/a0028235

James, V. R., Laura, C. T., Paul, J. F., Laurence, S., and Elizabeth, C. (2016). Impulse control and callous-unemotional traits distinguish patterns of delinquency and substance use in justice involved adolescents: examining the moderating role of neighborhood context. J. Abnorm. Child Psychol. 44, 599-611. doi: 10.1007/s10802-015-0057-0

Jessor, R. (1987). Problem-behaviors theory, psychosocial development, and adolescent problem drinking. Br. J. Addict. 82, 331-342. doi: 10.1111/j.1360-0443.1987.tb01490.x 
Ju, X. Y., Liu, X. W., and Fang, X. Y. (2011). Research on adolescent parents and peer attachement in relation to self-esteem and social adaptation (Chinese). Psychol. Dev. Educ. 27, 174-180. doi: 10.16187/j.cnki.issn1001-4918.2011.02.012

Keatley, D. A., Allom, V., and Mullan, B. (2017). The effects of implicit and explicit self-control on self-reported aggression. Personal. Individ. Differ. 107, 154-158. doi: 10.1016/j.paid.2016.11.046

Lam, C. B., Solmeyer, A. R., and McHale, S. M. (2012). Sibling differences in parent-child conflict and risky behaviors: A three-wave longitudinal study. J. Fam. Psychol. 26, 523-531. doi: 10.1037/a0029083

Laursen, B., and Collins, W. A. (2004). "Parent-child communication during adolescence" in Handbook of Family Communication, Mahwah, NJ: Erlbaum, 333-348.

Laursen, B., and Mooney, K. S. (2008). Relationship network quality: adolescent adjustment and perceptions of relationships with parents and friends. Am. J. Orthopsychiatry 78, 47-53. doi: 10.1037/0002-9432.78.1.47

Macek, P., and Jezek, S. (2007). Adolescents' assessments of parents and peers relationships to self-esteem and self-efficacy. Cesk. Psychol. 51, 26-36.

Maslowsky, J., Schulenberg, J., Chiodo, L. M., Hannigan, J. H., Greenwald, M. K., Janisse, J., et al. (2016). Parental support, mental health, and alcohol and marijuana use in national and high-risk African-American adolescent samples. Subst. Abuse: Res. Treat. 9, 11-20. doi: 10.4137/SART.S22441

Moore, S., Gullone, E., and McArthur, C. (2004). Risk taking and HIV/AIDS among young people in Cameroon: prediction of vulnerability using the adolescent risk-taking questionnaire. Soc. Behav. Personal. 32, 209-222. doi: 10.2224/sbp.2004.32.3.207

Muraven, M., Shmueli, D., and Burkley, E. (2006). Conserving self-control strength. J. Pers. Soc. Psychol. 91, 524-537. doi: 10.1037/0022-3514.91.3.524

O'Hara, R., and Cooper, M. (2015). Bidirectional associations between alcohol use and sexual risk-taking behaviors from adolescence into young adulthood. Arch. Sex. Behav. 44, 857-871. doi: 10.1007/s10508-015-0510-8

O'Hara, R. E., Gibbons, F. X., Gerrard, M., Li, Z. G., and Sargent, J. D. (2012). Greater exposure to sexual content in popular movies predicts earlier sexual debut and increased sexual risk taking. Psychol. Sci. 23, 984-993. doi: $10.1177 / 0956797611435529$

Özmen, O., and Sümer, Z. H. (2011). Predictors of risk-taking behaviors among Turkish adolescents. Personal. Individ. Differ. 50, 4-9. doi: 10.1016/j. paid.2010.07.015

Padilla-Walker, L. M., Nielson, M. G., and Day, R. D. (2016). The role of parental warmth and hostility on adolescents' prosocial behaviors towards multiple targets. J. Fam. Psychol. 30, 331-340. doi: 10.1037/fam0000157

Passos, J. A. F., Pires, A. V., Scheidt, L., de Almeida, L. A., Ferreira, C. F., Gubert, C., et al. (2015). Alcohol use in adolescence, impulsivity, and risk-taking behaviors in Wistar rats. Psychol. Neurosci. 8, 130-142. doi: 10.1037/h0101023

Patterson, G. R., Debaryshe, B. D., and Ramsey, E. (1989). A developmental perspective on antisocial behaviors. Am. Psychol. 44, 329-335. doi: 10.1037/0003-066X.44.2.329

Rubin, K. H., Dwyer, K. M., Kim, A. H., Burgess, K. B., Booth-LaForce, C., and Rose-Krasnor, L. (2004). Attachment, friendship, and psychosocial functioning in early adolescence. J. Early Adolesc. 24, 326-356. doi: $10.1177 / 0272431604268530$

Sameroff, A. J., and Mackenzie, M. J. (2003). Research strategies for capturing transactional models of development: the limits of the possible. Dev. Psychopathol. 15, 613-640. doi: 10.1017/S0954579403000312

Sentse, M., and Laird, R. D. (2010). Parent-child relationships and dyadic friendship experiences as predictors of behaviors problems in early adolescence. J. Clin. Child Adolesc. Psychol. 39, 873-884. doi: 10.1080/15374416.2010.517160

Shakespeare-Finch, J., and Obst, P. L. (2011). The development of the 2-way social support scale: a measure of giving and receiving emotional and instrumental support. J. Pers. Assess. 93, 483-490. doi: 10.1080/00223891.2011.594124

Skinner, O. D., and Mchale, S. M. (2016). Parent-adolescent conflict in African American families. J. Youth Adolesc. 45, 2080-2093. doi: 10.1007/ s10964-016-0514-2

Steinberg, L., and Morris, A. S. (2001). Adolescent development. Annu. Rev. Psychol. 2, 83-110. doi: 10.1146/annurev.psych.52.1.83

Tian, L. M., Chen, G. H., Wang, S. Q., Liu, H. J., and Zhang, W. X. (2012). Effects of parental support and friendship support on loneliness and depression during early and middle adolescence (Chinese). Acta Psychol. Sin. 44, 944-956. doi: 10.3724/SP.J.1041.2012.00944

Tian, L. M., Zhang, W. X., and Chen, G. H. (2014). Effects of parental support, friendship quality on loneliness and depression: to test an indirect effect model (Chinese). Acta Psychol. Sin. 46, 238-251. doi: 10.3724/SP.J.1041.2014.00238

Tu, J. J., Wan, J., Xiong, H. X., and Zhang, J. (2016). Parental support and college students' interpersonal adaptation: the mediating role of emotional intelligence. J. Psychol. Sci. 39, 964-969. doi: 10.16719/j.cnki.1671-6981.20160430

Tu, Y., and Yang, Z. (2016). Self-control as mediator and moderator of the relationship between social support and subjective well-being among the Chinese elderly. Soc. Indic. Res. 126, 813-828. doi: 10.1007/s11205-015-0911-Z

Vanassche, S., Sodermans, A. K., Matthijs, K., and Swicegood, G. (2014). The effects of family type, family relationships and parental role models on delinquency and alcohol use among flemish adolescents. J. Child Fam. Stud. 23, 128-143. doi: 10.1007/s10826-012-9699-5

Van der Graaff, J., Branje, S., De Wied, M., and Meeus, W. (2012). The moderating role of empathy in the association between parental support and adolescent aggressive and delinquent behaviors. Aggress. Behav. 38, 368-377. doi: 10.1002/ab.21435

Wang, H. J., and Lu, J. M. (2004). Establishment and survey of self-control scale of middle school students (Chinese). Psychol. Sci. 27, 1477-1482. doi: 10.16719/j.cnki.1671-6981.2004.06.055

Wang, M. T., Brinkworth, M., and Eccles, J. (2013). Moderating effects of teacher-student relationship in adolescent trajectories of emotional and behaviorsal adjustment. Dev. Psychol. 49, 690-705. doi: 10.1037/a0027916

Wang, Z., Kouvonen, A., Satka, M., and Julkunen, I. (2018). Parental social support and adolescent well-being: a cross-sectional study in China. Child Indic. Res. 12, 299-317. doi: 10.1007/s12187-018-9547-2

Watson, D., and Clark, L. A. (1993). "Behaviorsal disinhibition versus constraint: a dispositional perspective" in Handbook of Mental Control. eds. D. M. Wegner and J. W. Pennebaker (Englewood Cliffs, NJ: Prentice Hall), 506-527.

Wills, T. A., Ainette, M. G., Stoolmiller, M., Gibbons, F. X., and Shinar, O. (2008). Good self-control as a buffering agent for adolescent substance use: an investigation in early adolescence with time-varying covariates. Psychol. Addict. Behav. 22, 459-471. doi: 10.1037/a0012965

Wills, T. A., and Sandy, J. M. (2001). Family risk factors and adolescent substance use: moderation effects for temperament dimensions. Dev. Psychol. 37, 283-297. doi: 10.1037/0012-1649.37.3.283

Wood, A. P., Dawe, S., and Gullo, M. J. (2013). The role of personality, family influences, and prosocial risk-taking behaviors on substance use in early adolescence. J. Adolesc. 36, 871-881. doi: 10.1016/j.adolescence.2013.07.003

Yun, H. J., Cui, M., and Blair, B. L. (2016). The mediating roles of adolescent disclosure and parental knowledge in the association between parental warmth and delinquency among Korean adolescents. J. Child Fam. Stud. 25, 2395-2404. doi: $10.1007 /$ s10826-016-0425-6

Zhang, C., Zhang, L. J., and Shang, L. (2011). The questionnaire of risk-taking behaviors among adolescence-the reliability and validity of risk-taking behaviors scale in middle school students (Chinese). Chin. Ment. Health J. 25, 636-640. doi: 10.3969/j.issn.1000-6729.2011.08.018

Zhang, Y., and Xing, Z. J. (2007). A review on the research of the influence of social support on subjective well-being. Psychol. Sci. 30, 1436-1438. doi: 10.3969/j.issn.1671-6981.2007.06.037

Zimmerman, G. M., Botchkovar, E. V., Antonaccio, O., and Hughes, L. A. (2015). Low self-control in "bad" neighborhoods: assessing the role of context on the relationship between self-control and crime. Justice Q. 32, 56-84. doi: 10.1080/07418825.2012.737472

Conflict of Interest Statement: The authors declare that the research was conducted in the absence of any commercial or financial relationships that could be construed as a potential conflict of interest.

Copyright (c) 2019 Liu, Wang and Tian. This is an open-access article distributed under the terms of the Creative Commons Attribution License (CC BY). The use, distribution or reproduction in other forums is permitted, provided the original author(s) and the copyright owner(s) are credited and that the original publication in this journal is cited, in accordance with accepted academic practice. No use, distribution or reproduction is permitted which does not comply with these terms. 